\title{
El patrimonio paleontológico a partir de la experiencia de "Caminando sobre gliptodontes y tigres dientes de sable". Un proyecto de extensión universitaria en la Argentina
}

\author{
Facundo Iacona, Esteban Soibelzon, Raúl Montero, Martin R. Ciancio, Analía Francia, Victoria Penzo, Juan S. Salgado, Sergio \\ G. Rodriguez, M. Mercedes Gould, Victoria L. López, Malena Morell | Facultad de Ciencias Naturales y Museo, Universidad \\ Nacional de La Plata
}

URL de la contribución <www.iaph.es/revistaph/index.php/revistaph/article/view/4180>

Desde "Caminando sobre gliptodontes y tigres dientes de sable" (colectivo universitario de Argentina -provincia de Buenos Aires- que reúne estudiantes y graduados de biología, paleontología, antropología, geología, informática y artistas plásticas https://www.facebook.com/ proyectocaminando) abordamos la temática del patrimonio paleontológico como formador de identidad y como contenido transversal dentro de las Ciencias Naturales (CIANCIO; SOIBELZON; FRANCIA, 2015).

En Argentina existe la ley nacional 25743/03 de Protección del Patrimonio Arqueológico y Paleontológico. Sus primeros artículos indican: "...es objeto de la presente ley la preservación, protección y tutela del Patrimonio Arqueológico y Paleontológico como parte integrante del Patrimonio Cultural de la Nación y el aprovechamiento científico y cultural del mismo" y que "...forman parte del Patrimonio Paleontológico los organismos o parte de organismos o indicios de la actividad vital de organismos que vivieron en el pasado geológico [fósiles] y toda concentración natural de fósiles en un cuerpo de roca o sedimentos expuestos en la superficie o situados en el subsuelo o bajo las aguas jurisdiccionales". En esta ley se incluyen todos los fósiles, sin importar su antigüedad.

Desde Caminando sobre gliptodontes y tigres dientes de sable reflexionamos sobre qué es el patrimonio y si los fósiles forman parte de él. Sometiendo a debate la definición tradicional de patrimonio, originada en el derecho romano y vinculada a la herencia y posesiones de los individuos, ponemos en juego a los fósiles como bien patrimonial. Concluimos que un objeto cobra valor patrimonial cuando se comparte, es reconocido y sentido como propio por la comunidad. Esto es la base y razón por la cual las personas nos sentimos parte de un conjunto mayor que llamamos sentido de pertenencia; que puede ser local, nacional e incluso mundial. Así, el patrimonio juega un rol importante en nuestra identidad y su fuerza no proviene del objeto, sino de las personas que se apropian de él (SALGADO-AHUMADA; MONTERO; IACONA et ál., 2017). Apropiarnos del patrimonio es hacer parte de nosotros aquello que tiene un valor para la comunidad, entendiendo que no todos tenemos los mismos roles u obligaciones. Por ejemplo, los paleontólogos tienen responsabilidad en el descubrimiento, conocimiento, resguardo y divulgación de los fósiles; las instituciones deben trabajar junto a la comunidad local para darle valor educativo e identitario y velar por su cui-

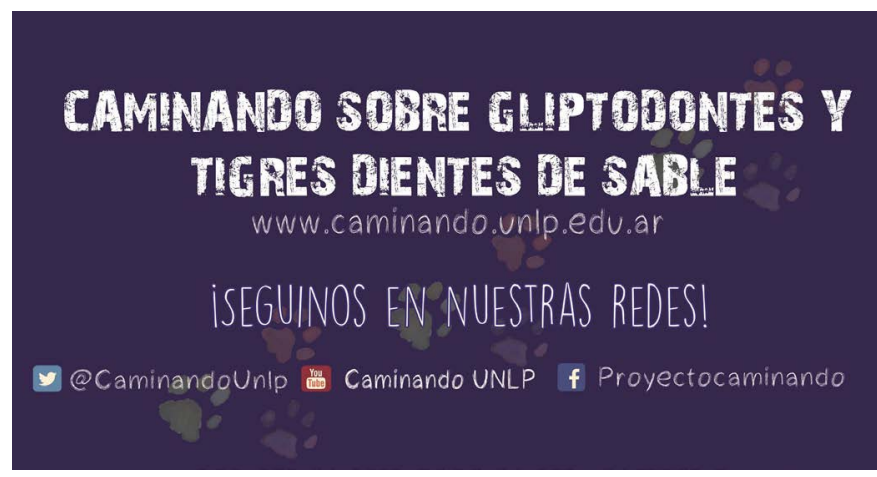

Caminando sobre gliptodontes y tigres dientes de sable en redes sociales 
a debate El marco legal para la protección del patrimonio paleontológico. ¿Qué pasa en tu comunidad?

dado. Analizamos el rol de instituciones (museos locales, organismos gubernamentales y educativos) y las acciones personales en pos de conservarlo y compartirlo.

Desde nuestra experiencia de varios años abordando la temática en diferentes espacios y públicos (escuelas, museos, jornadas de paleontología y patrimonio, etc.) surge que tendemos a identificarnos y compartir ciertos aspectos con la comunidad en la que vivimos como ser parte del entorno natural (por ejemplo, cerros y/o ríos), o bien creados por el hombre (como el lenguaje, arte, objetos y/o leyendas). Sentirse parte, compartir y que eso trascienda, debería ser un rol fundamental de la comunidad y una obligación del estado. Sin embargo, esto no ocurre. Con la globalización se desvanece el concepto de lo propio, de nuestra historia, del cómo llegamos a ser lo que somos, tergiversando la propia identidad. El hecho de compartir un mismo suelo nos brinda la posibilidad de encontrar allí elementos con los que identificarnos y que de esa manera conforman parte fundamental de nuestro patrimonio natural. Conocer nuestros fósiles, la historia que nos cuentan sobre nuestra región, discutir el por qué conservarlos, cuál es su aporte a nuestra cultura, cómo y dónde deben ser conservados para garantizar su acceso a la comunidad, les otorga valor patrimonial, al ser redescubiertos y compartidos (véase por ejemplo LORENZO; ROMITI; CHARNELLI, 2011; DE LOS REYES; SOIBELZON; ZURITA et ál., 2011; GALLIARI; AGUALLO; MAGNIN et ál., 2015; ACCETA; REY; IRRAZÁBAL, et ál., 2014).

Hay muchas cosas que podemos hacer, como parte de una sociedad, para la protección del patrimonio. Una sincera valoración de nuestro patrimonio a través de su conocimiento o enseñanza es una de las principales acciones que cualquier miembro de una sociedad puede cumplir. Es así que divulgar, conocer, valorar y admirar, son acciones importantes que podemos realizar, además de comprender que todos somos actores valiosos de este proceso a través del compromiso individual y colectivo, el cual es una condición necesaria para el cuidado de nuestro patrimonio. En este sentido, desde Caminando sobre gliptodontes y tigres dientes de sable

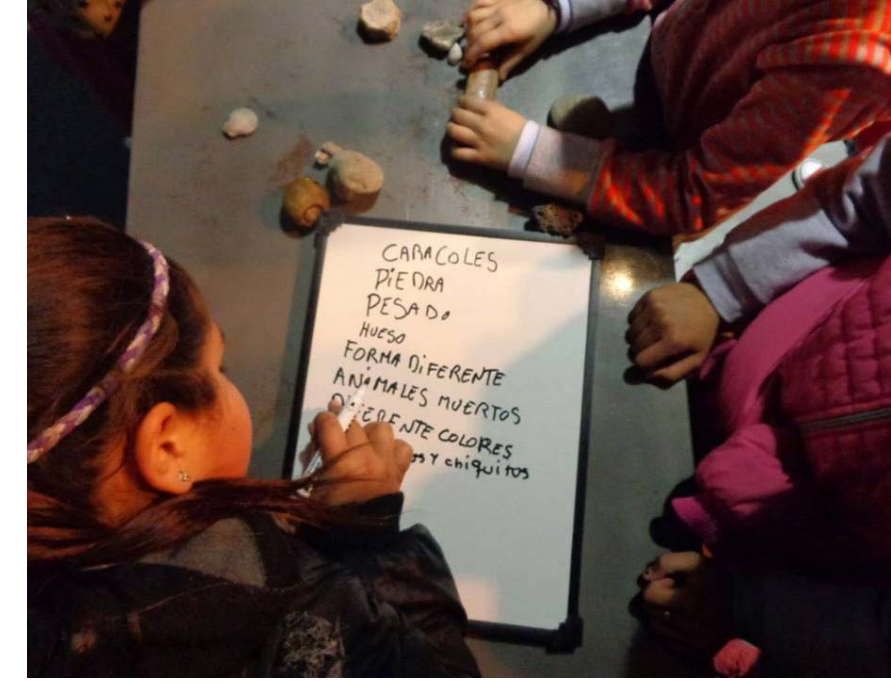

Taller abierto a la comunidad sobre paleontología y patrimonio | foto Esteban Soibelzon

elaboramos textos, audiovisual, audiocuentos y otras producciones didácticas que permiten abordar al patrimonio paleontológico y a las ciencias naturales desde infinidad de dimensiones y de distribución gratuita en nuestras redes.

En Argentina, si se produce el hallazgo casual de un fósil, el modo de proceder legalmente es comunicarse telefónicamente con la autoridad provincial de aplicación de la ley nacional. Cada provincia tiene sus propios órganos de control y aplicación, los cuales trabajan en conjunto (o deberían) con otras instituciones (como la policía y municipalidades). Otro camino para manifestar el hallazgo de un fósil es denunciarlo en la comisaría, municipio o museo local si lo hubiere. Dado que esta cadena no siempre resulta efectiva y en muchos casos termina en la pérdida del ejemplar, en nuestro país creamos la Red Paleontológica Pampeana (www.facebook. com/groups/503578769745632/about), que facilita y propicia vínculos entre museos, aficionados, profesionales, instituciones educativas, autoridades nacionales, provinciales y municipales, empresas y otros interesados. Tiene como objetivo optimizar los recursos de los museos, mejorar la transmisión de la información, resolver con eficiencia situaciones de rescates de restos 
a debate El marco legal para la protección del patrimonio paleontológico. ¿Qué pasa en tu comunidad?

fósiles, socializar la metodología de trabajo, permitir el acceso a información actualizada, compartir experiencias de trabajo y propiciar ayuda mutua entre los participantes. Organiza encuentros donde se discuten aspectos legales y sus aplicaciones, se elaboran documentos sobre temas de patrimonio y propuestas de gestión (REY; IPARAGUIRRE, 2011).

Este abordaje que promovemos respecto al patrimonio paleontológico impulsa su puesta en valor y fomenta su protección, favoreciendo la generación de una identidad colectiva que nos atraviesa como sociedad. Sin educación, la defensa del patrimonio concluye en un objetivo romántico que sólo interesará a una porción pequeña de la sociedad y por lo tanto será ineficaz en el contexto general (TONNI; TONNI, 2001).

\section{BIBLIOGRAFÍA}

- ACCETA, L.; REY, L.; IRRAZÁBAL, M. L.; ÁVILA, J. D. (2014) Entre tantos gliptodontes... "el gliptodonte". III Jornadas Paleontológicas del Centro (Olavarría, 12 y 13 de septiembre de 2014). Hacia una valoración de los museos regionales pampeanos. Libro de resúmenes [disponible en línea]<https://jor nadaspaleo.blogspot.com.es/2018/04/blog-post.html> [Consul ta: 30/04/2018]

- CAMINANDO sobre gliptodontes y tigres dientes de sable [documental en línea] <https://www.youtube.com/watch?v =cZy5PtevwfU> PARQUEE producciones, 2014 [Consulta: 24/ 04/2018]

- CIANCIO, M. R.; SOIBELZON, E.; FRANCIA, A. (ed.) (2015) Caminando sobre gliptodontes y tigres diente de sable. Una guía didáctica para comprender la evolución de la vida en la Tierra [disponible en línea]. Buenos Aires: EDULP (Editorial de la Universidad de La Plata), 2015 <http://sedici.unlp.edu.ar/ handle/10915/45658> [Consulta: 24/04/2018]

- DE LOS REYES, L. M.; SOIBELZON, L.; ZURITA, A.; POIRÉ, D.; ARROUY, M.; CANALICCHIO, J. M. (2011) Desde un Eosclerocalyptus a 8 metros de altura hasta la tranquila lectura en un sillón. II Jornadas Paleontológicas del Centro (Olavarría, 14 y 15 de octubre de 2011). Libro de resúmenes [disponible en línea] <https://jornadaspaleo.blogspot.com. es/2018/04/blog-post.html> [Consulta: 30/04/2018]

- GALLIARI, F.; AGUALLO, V.; MAGNIN, L.; MARTINS, E.; SARMIENTO, J.; SIMIOLI, J.; SCHIERFF, G. (2013) Rodeados De Fósiles: El Museo De La Plata y su relación con la ciudad.
En CIANCIO, M. R.; SOIBELZON, E.; FRANCIA, A. (ed.) Caminando sobre Gliptodontes y Tigres dientes de Sables. Una guía didáctica para comprender la evolución de la vida en la Tierra. Buenos Aires: EDULP (Editorial de la Universidad Nacional de La Plata), 2013, pp. 123-143

- LORENZO, J. M.; ROMITI, M.; CHARNELLI, E.; MEOQUI, L.; FRANCO, G. (2011) Génesis del museo Tuyu Mapu. Una experiencia comunitaria gral. Madariaga. Pcia. De Buenos Aires. II Jornadas Paleontológicas del Centro (Olavarría, 14 y 15 de octubre de 2011). Libro de resúmenes [disponible en línea] <https://jornadaspaleo.blogspot.com.es/2018/04/blog-post. html> [Consulta: 30/04/2018]

- REY, L.; IPARAGUIRRE, G. (2011) Resultados y Propuestas de Gestión del Taller: "Protegiendo el Patrimonio Paleontológico Provincial". II Jornadas Paleontológicas del Centro (Olavarría, 14 y 15 de octubre de 2011). Libro de resúmenes [disponible en línea] <https://jornadaspaleo.blogspot.com.es/2018/04/ blog-post.html> [Consulta: 30/04/2018]

- SALGADO AHUMADA, J.; MONTERO, R.; IACONA, F.; GOULD, M.; LÓPEZ, L. V.; MORELL, M.; RODRIGUEZ, S. G; UMENICO, M.; PANZERI, K.; FRANCIA, A.; CIANCIO, M. R.; SOIBELZON, E. (2017) ¿Deberíamos proteger los fósiles? IV Jornadas Paleontológicas del Centro - I Jornada de Arqueología. Claves para la preservación del patrimonio arqueológico y paleontológico (General Belgrano-Provincia de Buenos Aires, Argentina, 15 y 16 de septiembre de 2017). Libro de resúmenes [disponible en línea] <https://jornadaspaleo.blogspot.com. es/2018/04/blog-post.html> [Consulta: 30/04/2018]

- TONNI, E. P.; TONNI, A. (2001) Patrimonio paleontológico y arqueológico. Consideraciones sobre la integración del patrimonio cultural. Revista Museo, 3, 2001, pp. 23-29 